\title{
Site-Specific Labeling of RNA at Internal Ribose Hydroxyl Groups: Terbium-Assisted Deoxyribozymes at Work
}

\author{
Lea Büttner, Fatemeh Javadi-Zarnaghi, ${ }^{\dagger}$ and Claudia Höbartner* \\ Research Group Nucleic Acid Chemistry, Max Planck Institute for Biophysical Chemistry, Am Fassberg 11, 37077 Göttingen, \\ Germany
}

Supporting Information

ABSTRACT: A general and efficient single-step method was established for site-specific post-transcriptional labeling of RNA. Using $\mathrm{Tb}^{3+}$ as accelerating cofactor for deoxyribozymes, various labeled guanosines were site-specifically attached to 2 '$\mathrm{OH}$ groups of internal adenosines in in vitro transcribed RNA. The DNA-catalyzed 2',5'-phosphodiester bond formation proceeded efficiently with fluorescent, spin-labeled, biotinylated, or cross-linker-modified guanosine triphosphates. The sequence context of the labeling site was systematically analyzed by mutating the nucleotides flanking the targeted adenosine. Labeling of adenosines in a purine-rich environment showed the fastest reactions and highest yields. Overall, practically useful yields $>70 \%$ were obtained for 13 out of 16 possible nucleotide (nt) combinations. Using this approach, we demonstrate preparative labeling under mild conditions for up to 160-nt-long RNAs, including spliceosomal U6 small nuclear RNA and a cyclic-di-AMP binding riboswitch RNA.

\section{INTRODUCTION}

The site-specific attachment of labels onto RNA is of significant value in many areas of RNA chemical biology. The study of RNA folding and RNA-protein and RNA-ligand interactions by spectroscopic methods requires installation of observable reporter groups. Biochemical assays of RNA functions benefit from position-specific placement of reactive functional groups or probing agents. ${ }^{1}$ Emissive nucleotide (nt) analogues or abiotic functional groups for bioorthogonal labeling can be sitespecifically installed by solid-phase synthesis. ${ }^{2-4}$ Synthesis of RNAs longer than $\sim 40$ nt often involves enzymatic manipulation or ligation using $\mathrm{T} 4$ ligases or deoxyribozymes. $^{5-9}$ As alternatives to the fragment-based approach, direct post-transcriptional labeling methods are gaining increasing attention. Recent developments include the use of specific methyltransferases together with functionalized $S$ adenosylmethionine (SAM) analogues, as exemplified by the alkylation of a specific guanosine in $\mathrm{tRNA}^{\text {Phe }}$ with Trm $1 .^{10}$ More generally applicable may be the reconstitution of $\mathrm{C} / \mathrm{D}$ box small nucleolar ribonucleoprotein particles (snoRNPs), using guide RNAs responsible for the selection of the labeling site in the target RNA, as recently shown for the site-specific $2^{\prime}$ alkynylation of tRNA and mRNA. ${ }^{11}$ A non-enzymatic example of oligonucleotide-guided post-transcriptional RNA modification was introduced with the functionality transfer reaction from 6-thioguanosine in a donor DNA to the exocyclic amino groups of cytosine and guanine residues in the target RNA. $^{12-14}$ Particularly attractive was the combination of a guide and an enzyme in a single strand of DNA, introduced as "DNA-catalyzed labeling of RNA". ${ }^{15}$ In this approach, Baum and Silverman prepared a labeled tagging RNA by in vitro transcription using 5-aminoallyl-CTP and subsequent labeling by $N$-hydroxysuccinimide chemistry. This tagging RNA was then used as substrate for DNA-catalyzed ligation to the target RNA, forming labeled 2',5'-branched RNA. Despite the elegance of this approach, it has not been widely used in the RNA community. Limitations include the elaborate preparation of labeled tagging RNAs, as well as their inconvenient lengths of $8-17 \mathrm{nt}$, which could potentially interfere with RNA folding or functions.

In this contribution, we report the direct post-transcriptional installation of fluorescent, biotinylated, paramagnetic, and photoreactive mononucleotides at specific ribose $2^{\prime}-\mathrm{OH}$ groups within functional in vitro transcribed RNA. Key to this versatile approach is the use of deoxyribozymes as functional singlestranded DNA catalysts that have proven useful as tools for various applications in nucleic acids research. ${ }^{16-18} \mathrm{~A}$ particular deoxyribozyme, named 10DM24, originally developed by Silverman and co-workers for the synthesis of $2^{\prime}, 5^{\prime}$-branched RNA, ${ }^{19}$ was earlier shown to accept mononucleotides as substrates for ligation to adenosine branch sites. ${ }^{20} \mathrm{We}$ harnessed this catalytic ability of 10DM24 and established a mild and efficient labeling technique for RNA using chemically modified guanosine triphosphates (Scheme 1). A strategically positioned cytidine within the catalytic core of 10DM24 serves as a recognition nucleotide for guanosine triphosphates by Watson-Crick base-pairing at the center of a three-helix

Received: April 17, 2014

Published: May 13, 2014 


\section{Scheme 1. DNA-Catalyzed Labeling of $\mathrm{RNA}^{a}$}
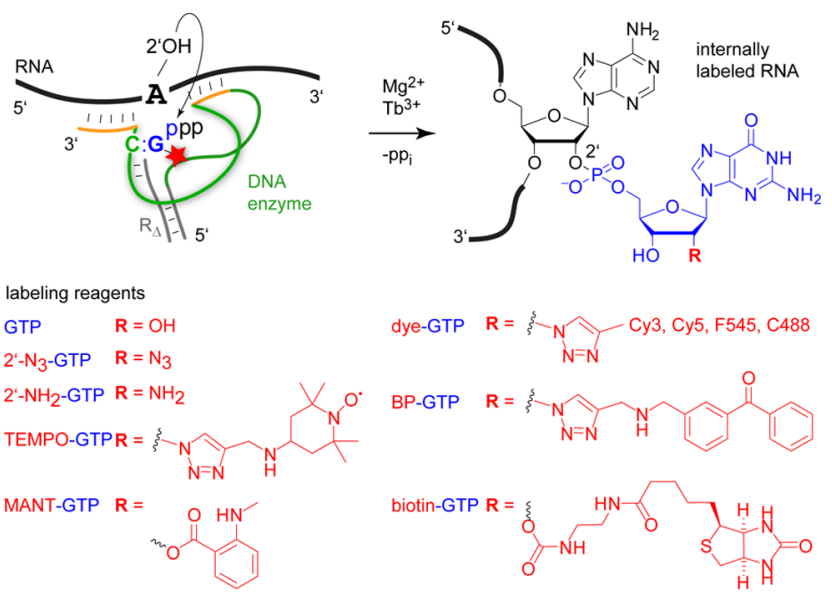

${ }^{a}$ Installation of bioorthogonal functional groups (azides or primary amines), spin labels, cross-linkers, affinity reagents, or fluorescent dyes using indicated GTP derivatives. The binding arms of the DNA enzyme select the target site in the RNA via hybridization (orange, binding arms; green, catalytic core; gray, third stem of $3 \mathrm{HJ}$ with $\mathrm{R}_{\Delta}$ ). The recognition nucleotide for GTP binding is explicitly indicated. A new phosphodiester bond is formed between the $2^{\prime}-\mathrm{OH}$ of the target adenosine and the $5^{\prime}$-phosphate of the labeled guanosine nucleotide upon incubation with $\mathrm{Mg}^{2+}$ and $\mathrm{Tb}^{3+}$ at $\mathrm{pH}$ 7.5. Various GTP derivatives used in this study are shown. TEMPO $=2,2,6,6-$ tetramethylpiperidinoxyl, MANT = methylanthraniloyl, $\mathrm{BP}=$ benzophenone. Structures of fluorophores Cy3, Cy5, and F545 are shown in Figure S1.

junction $(3 \mathrm{HJ})$ structure. $^{20}$ The target nucleoside in the RNA substrate is selected via hybridization of the DNA enzyme's binding arms (see Figure S2 for sequence information). In the presence of metal ion cofactors, a $2^{\prime}, 5^{\prime}$-phosphodiester bond is formed upon nucleophilic attack of the adenosine 2 '-OH group on the $\alpha$ phosphate of the labeled GTP and release of pyrophosphate. In contrast to the earlier DNA-catalyzed approach based on ligation of 17-nt-long fluorescently labeled tagging RNAs, ${ }^{15}$ our current method benefits from the small size of the labeled mononucleotide and the use of commercially available labeled GTP analogues. Capitalizing on our recent finding of lanthanides as accelerating cofactors for RNA-ligating deoxyribozymes, ${ }^{21}$ we now report highly beneficial effects of $\mathrm{Tb}^{3+}$ for DNA-catalyzed labeling of RNA. This finding was essential in establishing a general protocol for preparative labeling of RNA that works efficiently at $\mathrm{pH} 7.5$ and at practical concentrations of precious labeled GTP derivatives.

\section{RESULTS AND DISCUSSION}

Exploring the Substrate Scope and Establishing Mild Reaction Conditions for DNA-Catalyzed Labeling of RNA. Implementing deoxyribozymes as versatile tools for RNA labeling requires knowledge about acceptable modifications in the substrates to maintain high ligation efficiency. We tested various functional group mutations in the GTP substrate and found that ribose modifications, such as $2^{\prime}$-azido-, $2^{\prime}$-amino-, and $2^{\prime} / 3^{\prime}$-aminoethylcarbamoyl (EDA) functional groups, were well tolerated in the DNA-catalyzed reaction for labeling of RNA. Figure la shows the time course of the reactions for RNA R1 (for sequence see the Supporting Information) with $2 \mathrm{mM}$ GTP and $2^{\prime}$-modified analogues, resulting in quantitative labeling within $1-2 \mathrm{~h}$ at $37^{\circ} \mathrm{C}$. This successful DNA-catalyzed
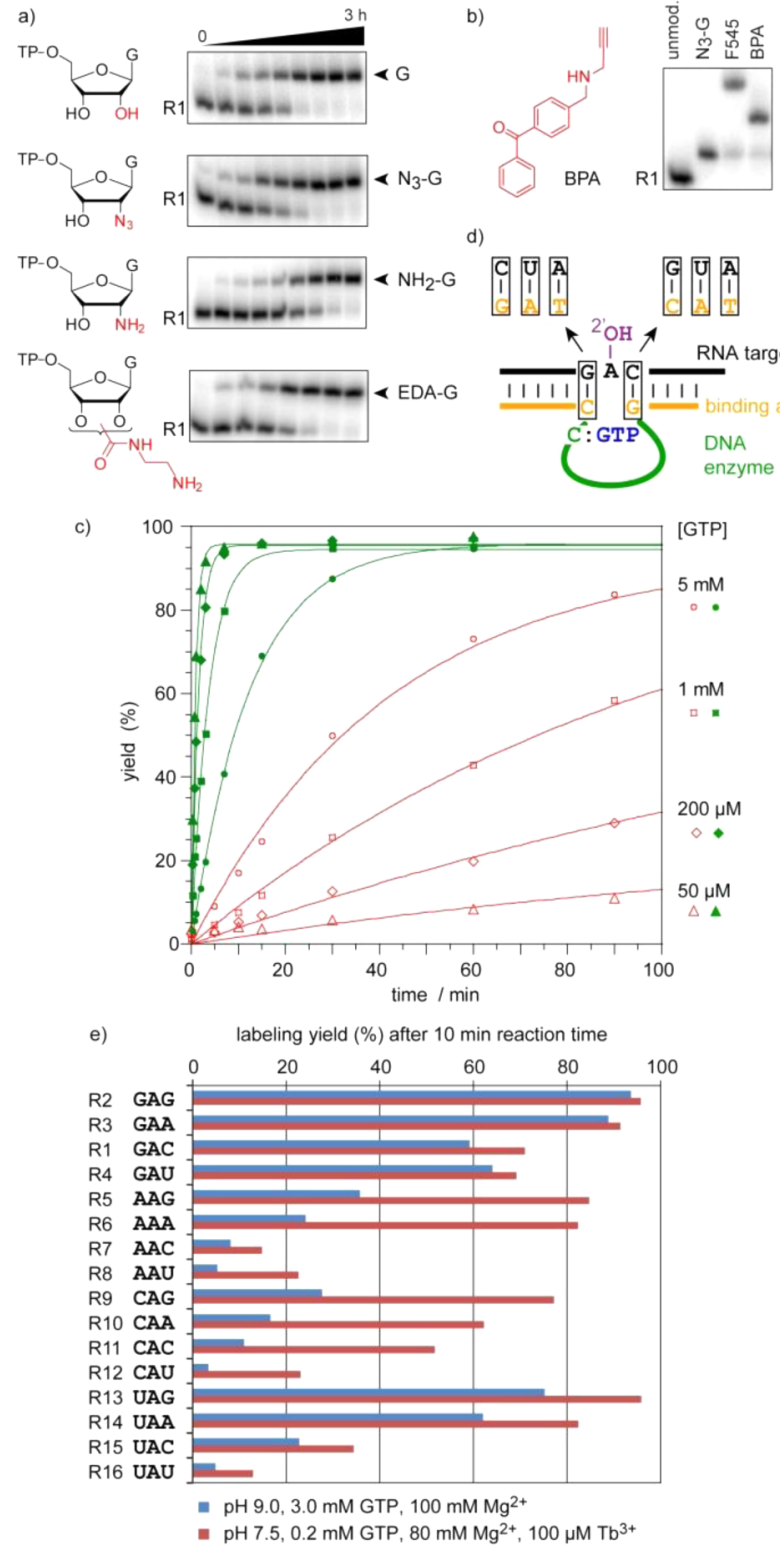

Figure 1. (a) Autoradiographs of PAGE analysis of DNA-catalyzed ligation of GTP and its $2^{\prime}$-modified analogues to RNA R1 with $2 \mathrm{mM}$ GTPs and $80 \mathrm{mM} \mathrm{Mg}^{2+}$ at $\mathrm{pH}$ 9.0. Reaction products are indicated by arrowheads. (b) PAGE analysis of CuAAC derivatization of $\mathrm{N}_{3}$-Glabeled R1, using 5 equiv of BPA or fluorescent F545-alkyne, $0.4 \mathrm{mM}$ $\mathrm{CuBr}, 0.8 \mathrm{mM}$ TBTA in $\mathrm{DMSO} / \mathrm{tBuOH} / \mathrm{H}_{2} \mathrm{O}$. (c) Accelerating effect of $\mathrm{Tb}^{3+}$ : nucleotide concentration-dependent kinetics of DNAcatalyzed GTP ligation to $\mathrm{R} 1$ at $\mathrm{pH} 7.5$, in the absence (red, empty symbols) or presence (green, filled symbols) of $100 \mu \mathrm{M} \mathrm{Tb}^{3+}$. Note the faster reactions at lower GTP concentrations with $\mathrm{Tb}^{3+}$. (d) Establishing generality of DNA-catalyzed labeling for 16 variants of R1. DNA enzymes maintained Watson-Crick base-pairing with the target RNA upstream and downstream of the labeling site. (e) Ligation yields for 16 target RNAs after $10 \mathrm{~min}$ reaction time under indicated conditions. PAGE = polyacrylamide gel electrophoresis, TBTA = tris[(1-benzyl-1H-1,2,3-triazol-4-yl)methyl]amine, TP = triphosphate.

reaction of ribose-modified GTP derivatives allows the installation of bioorthogonal functional groups that are normally not present in RNA. Fluorophores, spin labels, cross-linkers, and other structural probing agents can then be attached via well-known bioconjugation reactions, such as amide bond formation with active esters, or $3+2$ cycloaddition 
reactions, such as $\mathrm{Cu}(\mathrm{I})$-catalyzed azide-alkyne cycloaddition ( $\mathrm{CuAAC})$. We have demonstrated the viability of this approach with 2 '- $\mathrm{N}_{3}$-G-modified RNA which was derivatized via $\mathrm{CuAAC}$ using TEMPO- or benzophenone-modified alkynes (TA, BPA) or the commercially available alkyne of fluorophore F545 (Figure 1b). The cycloadditions were performed with TBTAcomplexed $\mathrm{Cu}(\mathrm{I})$ instead of in situ generated $\mathrm{Cu}(\mathrm{I})$ which requires, e.g., ascorbate as reducing agent. Thus, the integrity of the nitroxide radical and other sensitive reporter groups was maintained (see Supporting Information for details and additional examples for CuAAC conjugation of $2^{\prime}-\mathrm{N}_{3}$-G-labeled RNA, Figure S3). These results encouraged us to expand the labeling approach to larger RNA targets. However, incubation at $\mathrm{pH} 9.0$ in the presence of $\mathrm{Mg}^{2+}$ raises the general concern of RNA degradation, and using millimolar concentrations of modified GTP analogues may be prohibitive for economic reasons. $^{22}$

To expand the scope and applicability of DNA-catalyzed labeling of RNA, it is highly desirable to employ lower concentrations of labeled GTP at neutral $\mathrm{pH}$. Therefore, we analyzed the influence of reaction conditions on rate and yield. Decreasing the $\mathrm{pH}$ from 9.0 to 7.5 reduced the ligation rate 46-fold, and lowering the GTP concentration 10-fold from 2 $\mathrm{mM}$ to $200 \mu \mathrm{M}$ caused a further decrease of the ligation rate by a factor of $\sim 5$, resulting in rather slow reactions, which yielded $60-80 \%$ ligation product after $5 \mathrm{~h}$ incubation (Table 1 ).

Table 1. $\mathrm{pH}$ and Concentration Dependence of $k_{\mathrm{obs}}$ for DNA-Catalyzed Ligation of GTP, $2^{\prime}-\mathrm{N}_{3}-\mathrm{GTP}, 2^{\prime}-\mathrm{NH}_{2}$-GTP, and $2^{\prime} / 3^{\prime}$-EDA-GTP

\begin{tabular}{|c|c|c|c|c|c|c|}
\hline \multirow[b]{2}{*}{$\mathrm{pH}^{a}$} & \multirow[b]{2}{*}{$\begin{array}{l}{[\mathrm{NTP}]} \\
(\mathrm{mM})\end{array}$} & \multirow[b]{2}{*}{$\begin{array}{c}{\left[\mathrm{Tb}^{3+}\right]} \\
(\mu \mathrm{M})\end{array}$} & \multicolumn{4}{|c|}{$k_{\mathrm{obs}}\left(\min ^{-1}\right)$} \\
\hline & & & GTP & $\begin{array}{l}\mathrm{N}_{3^{-}} \\
\text {GTP }\end{array}$ & $\begin{array}{l}\mathrm{NH}_{2-}^{-} \\
\text {GTP }\end{array}$ & $\begin{array}{l}\text { EDA- } \\
\text { GTP }\end{array}$ \\
\hline 9.0 & 2 & 0 & 0.11 & 0.13 & 0.025 & 0.053 \\
\hline 7.5 & 2 & 0 & 0.016 & 0.034 & 0.004 & 0.009 \\
\hline 7.5 & 0.2 & 0 & 0.003 & 0.007 & 0.002 & 0.002 \\
\hline 7.5 & 0.05 & 0 & 0.001 & & & \\
\hline 7.5 & 0.2 & 100 & 0.67 & $\sim 1^{b}$ & $\sim 1^{b}$ & $\sim 1^{b}$ \\
\hline 7.5 & 0.05 & 100 & 1.2 & & & \\
\hline
\end{tabular}

${ }^{a} \mathrm{pH}$ 7.5, 50 mM HEPES; pH 9.0, $50 \mathrm{mM}$ CHES. Constant conditions for all experiments in this table: $150 \mathrm{mM} \mathrm{NaCl}, 2 \mathrm{mM} \mathrm{KCl}, 80 \mathrm{mM}$ $\mathrm{Mg}^{2+}, 37^{\circ} \mathrm{C} .{ }^{b}>50 \%$ product after $30 \mathrm{~s} ;>90 \%$ in $5 \mathrm{~min}$.

Inspired by our recent finding that lanthanide ions can impressively enhance the ligation rates for the DNA-catalyzed synthesis of $2^{\prime}, 5^{\prime}$-branched RNA, ${ }^{21}$ we explored the effect of $\mathrm{Tb}^{3+}$ on the activity of 10DM24 for single-nucleotide ligation.

All reactions with $\mathrm{Tb}^{3+}$ were performed at $\mathrm{pH} 7.5$, and it was found that $\mathrm{Tb}^{3+}$ drastically accelerated the reaction. The magnitude of the rate acceleration was dependent on the GTP concentration (Figure 1c). While addition of $100 \mu \mathrm{M} \mathrm{Tb}$ caused only 2 -fold faster reaction with $5 \mathrm{mM} \mathrm{GTP}$, the reaction was 200 -fold faster with $200 \mu \mathrm{M}$ GTP, and 1000-fold faster with $50 \mu \mathrm{M}$ GTP (Table 1, see also Figure S4). At first sight, this effect of faster rates at lower GTP concentrations may seem counter-intuitive, but it can be rationalized by considering the affinity of $\mathrm{Tb}^{3+}$ for phosphates (i.e., the effective concentration of $\mathrm{Tb}^{3+}$ is likely reduced due to triphosphate coordination at high GTP concentrations). Importantly, similar acceleration effects with $\mathrm{Tb}^{3+}$ were observed for $2^{\prime}$-modified GTP derivatives (Table 1); for example, $2^{\prime}-\mathrm{N}_{3}-\mathrm{GTP}, 2^{\prime}-\mathrm{NH}_{2}-\mathrm{GTP}$, and $2^{\prime} / 3^{\prime}$-EDA-GTP produced $>90 \%$ labeled RNA R1 in less than 10 min (Figure S5). Several nucleobase-modified GTP analogues that were potentially suitable for further bioconjugation were also tested, including 8-oxo-GTP, 6-thio-GTP and 8-(6-aminohexylamino)-GTP (8-AHA-G), but all of those derivatives reacted rather slowly and gave poorer yields (Figure S6).

Within the original sequence context of RNA R1 for which 10DM24 was selected, the reaction is most efficient for ligation at $2^{\prime}-\mathrm{OH}$ of adenosine. ${ }^{19}$ As the allowed sequence context around the adenosine target site has not been thoroughly investigated, ${ }^{23}$ we systematically explored adenosines flanked by all 16 possible dinucleotide combinations and examined the efficiency of GTP ligation at the target nucleosides (Figure 1d). Watson-Crick base-pairing with the DNA binding arms was maintained for each substrate (see Supporting Information for sequences). Figure 1e depicts the labeling yields for all 16 RNA substrates after $10 \mathrm{~min}$ reaction time, using either $3 \mathrm{mM}$ GTP at $\mathrm{pH} 9$ with $100 \mathrm{mM} \mathrm{Mg}^{2+}$, or $200 \mu \mathrm{M}$ GTP at $\mathrm{pH} 7.5$ with 80 $\mathrm{mM} \mathrm{\textrm {Mg } ^ { 2 + }}$ and $100 \mu \mathrm{M} \mathrm{Tb}^{3+}$ (kinetic data are given in Table S2).

Several interesting conclusions were drawn from these experiments. First, the ligation efficiency at high $\mathrm{pH}$ and high GTP concentration was strongly sequence-dependent. Second, the efficiency for all RNA substrates was strongly improved by adding $\mathrm{Tb}^{3+}$ and reducing the GTP concentration. Under these conditions, labeling was fast and high-yielding ( $80 \%$ in $10 \mathrm{~min}$ ) for adenosines that were followed by a purine in the $3^{\prime}$ direction. For adenosines followed by a pyrimidine nucleotide, ligation yields were very good when the 5 '-neighbor was guanosine but lower for other 5 '-neighbors. Overall, 9 out of 16 substrates yielded $>70 \%$ labeled RNA in $10 \mathrm{~min}$, and four additional RNAs yielded $>70 \%$ labeled product in $2 \mathrm{~h}$ (Figure S7). Summarizing these results, -NAR- and -GAY- are the preferred sequence contexts for target adenosines for DNAcatalyzed labeling with 10DM24 ( $\mathrm{N}=$ any nucleotide, $\mathrm{R}=$ purine, $\mathrm{Y}=$ pyrimidine). For preparative reactions, reliable conditions for various target RNAs and $2^{\prime}$-modified GTPs were found using RNA concentrations of 5-20 $\mu \mathrm{M}$, with as little as 4-5 equiv of labeled GTP. The corresponding deoxyribozyme in complex with $\mathrm{R}_{\Delta}$ was used in stoichiometric ratio with respect to target RNA. Preparative incubation was performed at $37{ }^{\circ} \mathrm{C}$ for $1-2 \mathrm{~h}$, or at $22{ }^{\circ} \mathrm{C}$ for $3-5 \mathrm{~h}$.

Having established mild and economic reaction conditions, we examined the reaction of GTP analogues with larger ribose modifications that would allow fluorescent labels or affinity tags to be directly installed on the RNA target in a single DNAcatalyzed reaction step. We tested a series of commercially available ribose-labeled GTP analogues and found that, e.g., 2' / 3'-MANT-GTP and 2' /3'-EDA-linked biotin- or Cy3-modified GTP gave high yields of labeled RNA (Figures 2a and S8). Encouraged by these results, we synthesized various labeled GTP analogues by $\mathrm{CuAAC}$, using $2^{\prime}-\mathrm{N}_{3}$-GTP and propargylated derivatives of TEMPO (TA, serving as spin label) or benzophenone (BPA, to be used as UV-inducible cross-linker), as well as commercial alkynes of fluorescent dyes, including C488, F545, Cy3, and Cy5 analogues. The labeled GTPs were purified by RP-HPLC (Figure S9) and then used in the DNAcatalyzed labeling reactions with $\mathrm{Tb}^{3+}$ as cofactor (Figure $2 \mathrm{~b}$ ). All "click"-labeled GTPs were efficient substrates and produced the site-specifically labeled RNAs in high yields with fast reaction rates $\left(k_{\mathrm{obs}} \approx 1 \mathrm{~min}^{-1}\right.$, Figure S10). Using 4 equiv of labeled GTPs with $100 \mu \mathrm{M} \mathrm{Tb}^{3+}$ and $20 \mathrm{mM} \mathrm{Mg}^{2+}$ at $\mathrm{pH} 7.5$ resulted in $>80 \%$ labeled RNA within 30 min for most labeled 


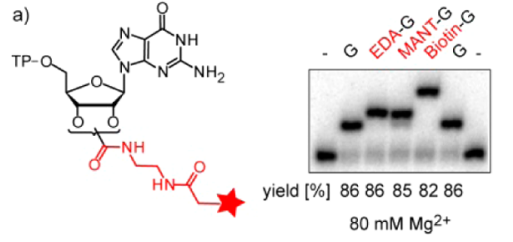

b)
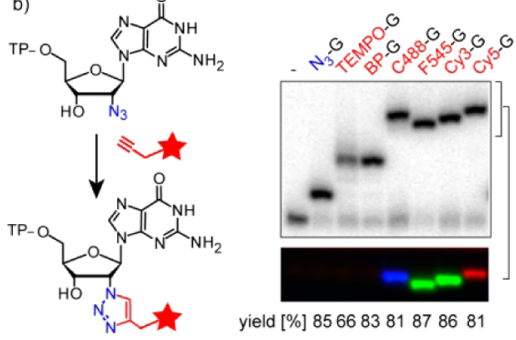

yield [\%] 85668381878681
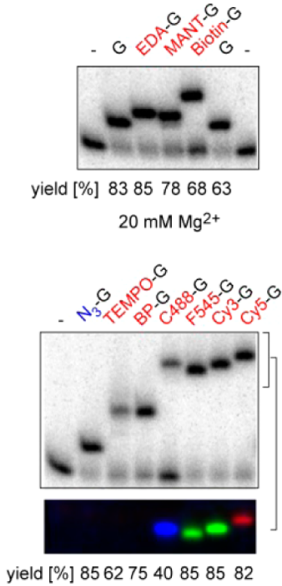

Figure 2. DNA-catalyzed labeling of RNA with ribose-modified GTPs. (a) Using commercial carbamoyl-linked MANT and biotin-labeled GTP in comparison to unmodified GTP and EDA-GTP. RNA R1 was used at $5 \mu \mathrm{M}$ with $20 \mu \mathrm{M}$ GTP (or labeled GTP), at pH 7.5, with 100 $\mu \mathrm{M} \mathrm{Tb}^{3+}, 37^{\circ} \mathrm{C}, 30 \mathrm{~min}$. Gel images compare labeling yields obtained with $80 \mathrm{mM} \mathrm{Mg}^{2+}$ (left) and $20 \mathrm{mM} \mathrm{Mg}{ }^{2+}$ (right). (b) Labeled GTP derivatives synthesized by CuAAC (see Supporting Information for details) were used under the same conditions as in panel a. Below the autoradiograph is shown an overlay of fluorescence images (epi illumination with blue, green, and red LEDs).

GTP analogues (Figure 2). Reactions were 2-4-fold faster with $80 \mathrm{mM} \mathrm{Mg}{ }^{2+}$, but high metal ion concentrations might be suboptimal for long RNA targets. Below $20 \mathrm{mM} \mathrm{Mg}^{2+}$ the reactions were too slow to be of practical use (Table S3). Labeled RNAs were isolated and characterized by ESI-MS, thermal melting, and EPR spectroscopy (Table S4, Figure S11).

DNA-Catalyzed Labeling of RNA for FRET: Confirming the Innocence of 2'-Attached Guanosine Labels. To demonstrate the generality of this labeling strategy, we examined the influence of $2^{\prime}$-labeling on stability, folding, and function of various RNAs. As a first example we discuss a 46-bp RNA duplex that was labeled with two fluorophores, Cy3-G and $\mathrm{Cy} 5-\mathrm{G}$, that form a well-known FRET pair. Cy3-G was installed at two different positions, A16 or A24 of strand A, and Cy5-G was installed at $\mathrm{A}^{\prime} 0^{\prime}$ of the complementary strand $\mathrm{B}$ (Figure 3a). Labeling efficiency was $>85 \%$, and isolated yields were $50-62 \%$ (4 nmol of RNA). Labeled and unlabeled strands $A$ and $B$ were used to prepare five duplex samples (I-V), containing none (I), one (II, III), or two labels (IV, V). The double-labeled samples contained the donor and acceptor fluorophores in opposite strands, separated by 13 or $21 \mathrm{bp}$. HPLC and UV-vis spectrophotometry confirmed an equimolar ratio of quantitatively labeled strands (Figures 3 and S12). Thermal melting experiments revealed that the labeled guanosines linked to the 2 '-OH of adenosine branch sites caused only minor destabilization of the duplex. Single-labeled duplexes had the $T_{\mathrm{m}}$ lowered by $1.5-2{ }^{\circ} \mathrm{C}$, and the $T_{\mathrm{m}}$ of double-labeled duplexes dropped by less than $4{ }^{\circ} \mathrm{C}$. As expected, the FRET efficiency was higher for duplex IV (Cy3 and $\mathrm{Cy} 5$ separated by $13 \mathrm{bp}$ ) than for duplex V (Cy3 and Cy5 separated by $21 \mathrm{bp}$ ) (Figure $3 \mathrm{~d}$ ).

As a second example we chose to study a ligand-binding RNA. The 52-nt aptamer domain of the SAM-II riboswitch folds into a pseudoknot structure upon binding SAM in the presence of $\mathrm{Mg}^{2+}$ (Figure 4a). ${ }^{24,25}$ Structure and folding of SAM-II have been well studied by various techniques, ${ }^{24-27}$
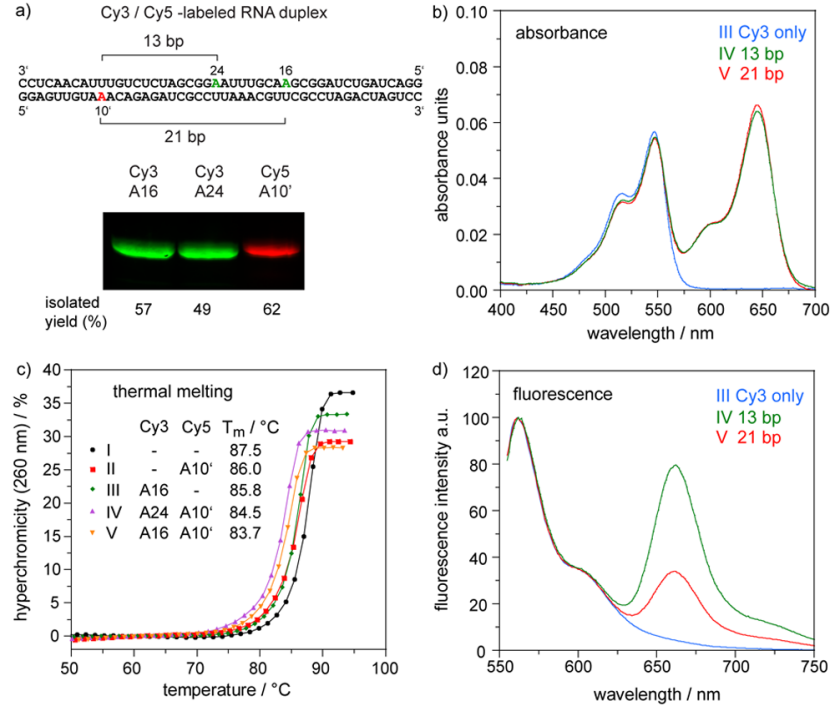

Figure 3. DNA-catalyzed labeling of RNA and characterization by FRET. (a) Sequence of 46-bp duplex with label positions indicated. Overlay of fluorescence images of PAGE for purification of labeled RNAs: Cy3 is green, Cy5 is red. (b) UV-vis absorption spectra. (c) UV melting curves. Conditions for panels b and c: $0.4 \mu \mathrm{M}$ duplex in 10 $\mathrm{mM}$ potassium phosphate $\mathrm{pH} 7.0,150 \mathrm{mM} \mathrm{NaCl}$. (d) Normalized fluorescence emission spectra upon donor excitation (at $545 \mathrm{~nm}, 0.1$ $\mu \mathrm{M}$ RNA, $50 \mathrm{mM}$ KMOPS $\left.\mathrm{pH} 7.5,100 \mathrm{mM} \mathrm{KCl}, 20{ }^{\circ} \mathrm{C}\right)$.
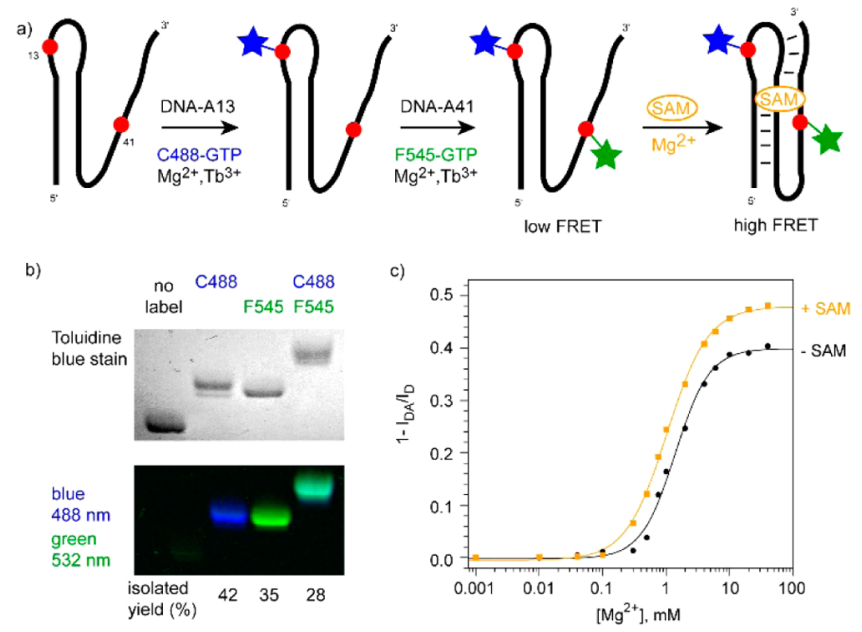

Figure 4. (a) DNA-catalyzed labeling of SAM-II RNA and analysis of pseudoknot folding by FRET. (b) Images of PAGE analysis of unlabeled, single-labeled, and double-labeled RNAs with C488-G at A13 and F545-G at A41. Conditions: 10\% PAGE, 35 W, 2.5 h. (c) $\mathrm{Mg}^{2+}$-dependent folding monitored by FRET in the absence and presence of $10 \mu \mathrm{M}$ SAM. Conditions: $0.1 \mu \mathrm{M}$ RNA, $50 \mathrm{mM}$ KMOPS $\mathrm{pH} 7.5,100 \mathrm{mM} \mathrm{KCl}, 20^{\circ} \mathrm{C} . I_{\mathrm{DA}}=$ fluorescence emission intensity at $520 \mathrm{~nm}$ of double-labeled RNA, $I_{\mathrm{D}}=$ emission intensity at $520 \mathrm{~nm}$ of donor-labeled RNA; excitation at $496 \mathrm{~nm} .\left[\mathrm{Mg}^{2+}\right]_{1 / 2}(+\mathrm{SAM})=1.0$ $\mathrm{mM} ;\left[\mathrm{Mg}^{2+}\right]_{1 / 2}(-\mathrm{SAM})=1.4 \mathrm{mM}$.

providing a solid basis for testing our RNA labeling method. To examine the influence of 2 -attached labeled guanosines on ligand binding, we used a previously described strategy based on 2-aminopurine (2AP) fluorescence. ${ }^{26}$ Changes in $2 \mathrm{AP}$ fluorescence upon titration with SAM provide a measure for ligand affinity. Labeled SAM-II RNAs were prepared with 2AP on position 14 and a guanosine label at the $2^{\prime}-\mathrm{OH}$ group of A41. Alternatively, 2AP was introduced at position 41 and 
guanosine attached to A9 or A13 (Figure S13), and fluorescence changes were monitored in SAM titration experiments. The binding constants ranged from 0.4 to 2.1 $\mu \mathrm{M}$ (Figure S14) and were consistent with reported data, ${ }^{24,26}$ confirming that the guanosine labels do not interfere with ligand binding. To demonstrate SAM-II RNA folding by FRET, we installed $\mathrm{C} 488-\mathrm{G}$ at $2^{\prime}-\mathrm{OH}$ of $\mathrm{A} 13$ and F545-G at $\mathrm{A} 41$ by two successive DNA-catalyzed labeling reactions. PAGE analysis confirmed the presence of both labels, by the detectable reduced mobility and by the overlapping fluorescence signal of both chromophores (Figure 4b). The FRET efficiency was monitored upon $\mathrm{Mg}^{2+}$-induced folding of the pseudoknot structure in the presence and absence of SAM (Figures $4 \mathrm{c}$ and S15). The observed left-shifted $\left[\mathrm{Mg}^{2+}\right]_{1 / 2}$ value in the presence of SAM was expected and consistent with reported data, ${ }^{28}$ confirming the intact functionality of the FRET-labeled RNA.

Direct DNA-Catalyzed Labeling of Large RNA Transcripts. Many interesting functional RNAs are longer than the $\sim 50$ nt RNA discussed in the previous section. We chose two examples of longer non-coding RNAs and examined DNAcatalyzed attachment of fluorescent reporter groups. The 120nt-long spliceosomal U6 $\operatorname{snRNA}^{29}$ was labeled with the fluorescent reporter MANT-G at 10 positions (Figure 5a, b), which were selected on the basis of the sequence preferences of target adenosines. Analysis of labeling efficiencies becomes more difficult for such larger targets since labeled and unlabeled RNAs have equal electrophoretic mobilities. We demonstrate that labeling yields can easily be determined upon site-specific cleavage into shorter fragments using the well-known RNAcleaving deoxyribozymes $8-17$ or $10-23$ (Figures $5 \mathrm{c}$ and S16). ${ }^{16}$ Labeling of U6 snRNA at any targeted position between A40 and A56 was analyzed by cleavage of an analytical aliquot of each labeled RNA at nts 35 and 62, resulting in labeled 27-mers, which can easily be distinguished from the unlabeled 27-mer upon denaturing PAGE separation (Figure 5d). Similarly, labeling between A62 and A94 was analyzed after cleavage at positions 51 and 97, resulting in labeled 46-mers which were separated and quantified (Figure 5e). The observed labeling efficiencies correlated well with the predictions based on the sequence context. For example, A51 which is embedded between guanosines was almost quantitatively labeled, while A41, residing in an unfavorable sequence context (AAC), was poorly labeled. Overall, six tested sites were labeled with $>75 \%$, two reached $40-50 \%$, and three sites did not give preparatively useful yields. The result for A76 (which was predicted to be a good labeling site on the basis of its sequence context AAG) showed only $15 \%$ MANT-G attached. This hints toward the influence of strong secondary structure elements that limit the accessibility for deoxyribozyme hybridization. Using strategically positioned disruptor oligonucleotides, double-stranded secondary structures can be broken to improve the labeling efficiency for difficult sites.

Another structured RNA addressed in this work is the 156nt-long ydaO riboswitch RNA (Figure 5f), which was recently reported to bind cyclic-di-AMP with sub-nanomolar affinity. ${ }^{30,31}$ Details about folding and dynamics of this RNA upon ligand binding are not yet known. Single-molecule FRET of double-labeled RNAs has proven to be a highly valuable method to study riboswitch RNAs. ${ }^{32-34}$ To prepare labeled derivatives for spectroscopic studies, we targeted the DNAcatalyzed installation of a FRET pair on the ydaO RNA. As an example, we chose A46 and A125 as target sites for labeling a) U6 snRNA (S.cer.)

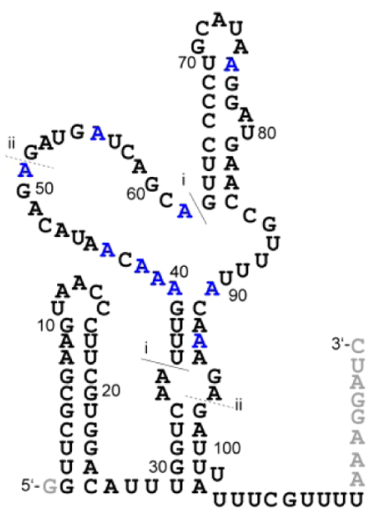

b) MANT-G-labeled U6 snRNA

d) analysis of labeling (cut i) fragment 36-52

- 404142445156

$27 n t$

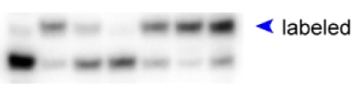

$7324<5729079$ \% (yield)

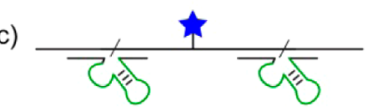

DNA-catalyzed

RNA-cleavage (cut)

for analysis of

labeling efficiency

e) analysis of labeling (cut ii) fragment 52-97

62769194

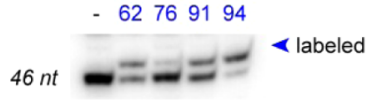

$48 \quad 154180 \%$ (yield)

f) ydaO riboswitch RNA (B.subt.)

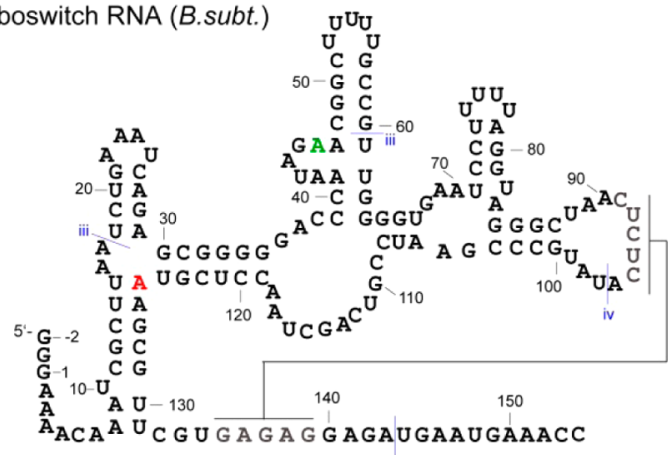

g)

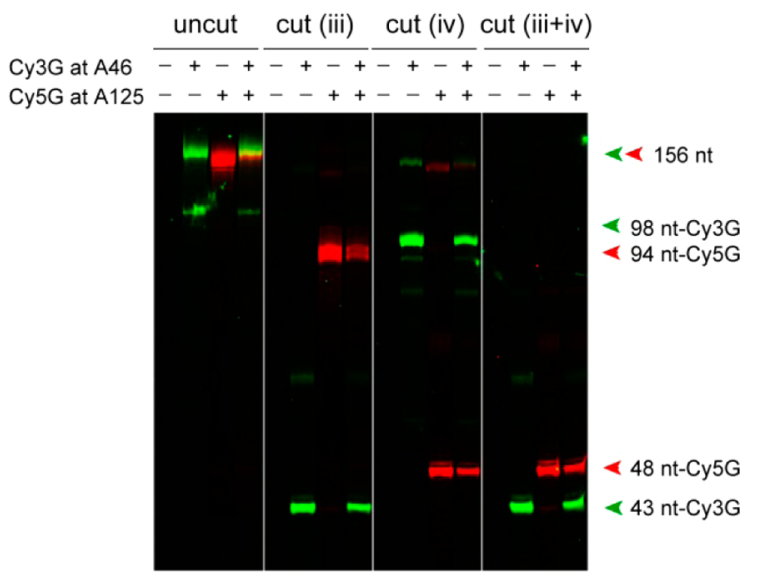

Figure 5. DNA-catalyzed labeling of large RNAs. (a) U6 snRNA sequence; adenosines tested as labeling sites are marked in blue. (b) PAGE image of purification of 10 MANT-G-labeled U6 snRNA samples (10\% PAGE). (c) Schematic of DNA-catalyzed RNA cleavage (cut) for analysis of labeling efficiency. (d) Analysis after cut i at A35 and A62. (e) Analysis after cut ii at A51 and A97. For d and e, 15\% PAGE, full gel image in Figure S17). (f) ydaO riboswitch RNA sequence. Cy3 is installed at A46 and Cy5 at A125. (g) Fluorescence images of PAGE analysis of uncut and cut ydaO RNA samples; 15\% PAGE, corresponding autoradiography gel image in Figure S18.

with Cy3- and Cy5-GTP, according to the established labeling conditions described above. A DNA oligonucleotide comple- 
mentary to nts 57-89 was included as disruptor of secondary structures to facilitate hybridization of the labeling deoxyribozymes. Samples with only donor or only acceptor dye were prepared by a single DNA-catalyzed labeling step. For installation of the second dye, the single-labeled RNA was first isolated by PAGE and then subjected to a second labeling reaction with the other fluorophore. By splitting the singlelabeled RNAs for several reactions, this stepwise approach allows parallel synthesis of a library of double-labeled RNAs for screening several donor-acceptor distances. The fluorescence scans of the polyacrylamide gel analysis showed overlapping emission bands in the red and green channels, confirming the attachment of both dyes in the double-labeled sample. To determine the efficiency of labeling at each site, analytical aliquots were cut by RNA-cleaving deoxyribozymes at positions 17 and 60 (cut iii), resulting in a Cy3-labeled 43-mer and a Cy5-labeled 94-mer, or at positions 96 and 143 (cut iv), giving a Cy3-labeled 98-mer and a Cy5-labeled 47-mer (Figure 5g). Efficiency of Cy3-G labeling at A46 was 60\%, and Cy5-G was attached at A125 with $38 \%$ yield (Figure S18). In an approach similar to the analysis by RNA-cleaving deoxyribozymes, labeled transcripts can be enriched by digestion of the unlabeled RNA due to the remaining accessibility of the $2^{\prime}$ $\mathrm{OH}$ for transesterification. ${ }^{35}$

These results demonstrate that various fluorescent labels can be conjugated to long RNAs with the DNA-catalyzed approach developed in this work. With the ability to attach biotinylated guanosine in an analogous fashion, this method will make immobilizable FRET-labeled RNAs for single-molecule studies accessible from long unmodified transcripts. Labeling reactions addressing different target sites can easily be performed in parallel, providing rapid access to a collection of fluorescent RNAs for probing RNA folding landscapes. In addition, the deoxyribozymes can be isolated upon PAGE purification of the labeled RNAs and reused in subsequent reactions.

\section{CONCLUSIONS}

In summary, we have established a general RNA labeling method using ribose-modified guanosine triphosphates as labeling reagents and $\mathrm{Tb}^{3+}$-assisted DNA catalysts to install fluorophores, spin labels, and cross-linkers at $2^{\prime}-\mathrm{OH}$ groups of internal adenosines in in vitro transcribed RNA. Systematic investigation of labeling efficiencies resulted in guidelines for selecting labeling sites on the basis of sequence context and secondary structure. This approach will be widely applicable for labeling diverse RNAs for structural and functional studies. For example, we envision labeling of mRNAs for single-molecule FRET studies of RNA splicing and cross-linking experiments to examine various non-coding RNAs and their interactions with proteins. We point out that this approach holds the potential for orthogonal DNA-catalyzed labeling of RNA, as engineering of the recognition nucleotide will switch the specificity to other labeled nucleotides, based on Watson-Crick base-pairing. ${ }^{20}$ For example, a donor-labeled ATP and an acceptor-labeled GTP can then be used simultaneously with the corresponding DNA enzymes in a one-pot FRET labeling reaction. In addition, new deoxyribozymes for labeling of RNA target sites other than adenosine will further broaden the generality of the method.

\section{METHODS}

Materials and General Methods. Deoxyribozymes were purchased as unmodified DNA oligonucleotides. RNAs were prepared by solid-phase synthesis or by in vitro transcription according to the procedures previously described and commonly used in our laboratory. ${ }^{36}$ The DNA template for transcription of ydaO RNA was prepared by overlapping primer extension. A pUC18 plasmid containing U6 snRNA sequence from S. cerevisiae was kindly provided by Prof. Reinhard Lührmann (MPI for Biophysical Chemistry). Modified GTP analogues used in this study were purchased from TriLink Biotechnologies or Jena Bioscience.

Synthesis of Labeled GTPs by CuAAC. A solution of $2^{\prime}-\mathrm{N}_{3}$-GTP ( $100 \mathrm{nmol}, 1$ equiv) in $24 \mu \mathrm{L}$ of $\mathrm{H}_{2} \mathrm{O}$ and $10 \mu \mathrm{L}$ of DMSO/tBuOH 3:1 was mixed with $3 \mu \mathrm{L}$ of alkyne solution ( $100 \mathrm{mM}$; 3 equiv) and combined with a freshly prepared mixture of $\mathrm{CuBr}(1 \mu \mathrm{L}$ of $88 \mathrm{mM}$ in $\mathrm{DMSO} / \mathrm{tBuOH} 3: 1 ; 0.9$ equiv) and TBTA $(2 \mu \mathrm{L}$ of $88 \mathrm{mM}$ in $\mathrm{DMSO} / \mathrm{tBuOH} 3: 1 ; 1.7$ equiv) to give a final volume of $40 \mu \mathrm{L}$. Alkynes were synthesized (TA, BPA, see Supporting Information) or purchased from Jena Bioscience or Baseclick. The solution was incubated at room temperature for $4 \mathrm{~h}$ and precipitated by addition of $1.2 \mathrm{~mL}$ of ice-cold $2 \% \mathrm{NaClO}_{4}$ in acetone, followed by centrifugation at $4{ }^{\circ} \mathrm{C}, 13200 \mathrm{rpm}$ for $30 \mathrm{~min}$. The crude sample was dissolved in water and purified by reversed-phase HPLC on a Nucleosil 100-5 C18 $\mathrm{HD}$ column at $40{ }^{\circ} \mathrm{C}$ (buffer $\mathrm{A}, 100 \mathrm{mM}$ TEAA in $\mathrm{H}_{2} \mathrm{O}$; buffer $\mathrm{B}, 20$ $\mathrm{mM}$ TEAA in $\left.\mathrm{H}_{2} \mathrm{O}: \mathrm{MeCN} 1: 4\right)$. The isolated yield ranged from 45 to $76 \%$. The products were characterized by ESI-MS (see Table S1).

Kinetic Assays of DNA-Catalyzed RNA Labeling Reactions. The $5^{\prime}{ }^{32} \mathrm{P}$-labeled target RNA ( $\left.2 \mathrm{pmol}\right)$, the respective deoxyribozyme, and $\mathrm{R}_{\Delta}$ were mixed in a 1:5:10 ratio and annealed in $25 \mathrm{mM}$ HEPES $\mathrm{pH} \mathrm{7.5,} 15 \mathrm{mM} \mathrm{NaCl}$, and $0.1 \mathrm{mM}$ EDTA $\left(95{ }^{\circ} \mathrm{C}, 2 \mathrm{~min}\right.$, slowly cooling to room temperature, $15 \mathrm{~min}$ ). The assays were performed in $10 \mu \mathrm{L}$ volume at $37^{\circ} \mathrm{C}$ in $50 \mathrm{mM}$ HEPES $\mathrm{pH} 7.5$ or in $50 \mathrm{mM}$ CHES pH 9.0, including $150 \mathrm{mM} \mathrm{NaCl}$ and $2 \mathrm{mM} \mathrm{KCl}$. For screening of reaction conditions, GTP was used at concentrations of $50 \mu \mathrm{M}$ to $5 \mathrm{mM}$, and $\mathrm{MgCl}_{2}$ at 3-80 mM. Reactions in the presence of $\mathrm{Tb}^{3+}$ contained $100 \mu \mathrm{M} \mathrm{TbCl}$. Kinetic assays with labeled GTP analogues used $50-200 \mu \mathrm{M}$ nucleotide and $100 \mu \mathrm{M} \mathrm{TbCl}_{3}$. Aliquots of $0.8-1.0 \mu \mathrm{L}$ were removed at desired time points and quenched into stop solution ( $80 \%$ formamide, $1 \times \mathrm{TBE}, 50 \mathrm{mM}$ EDTA, $0.025 \%$ each bromophenol blue and xylene cyanol). The samples were analyzed by PAGE (20\% polyacrylamide), and band intensities were quantified by PhosphorImaging. The yield versus time data were fit to yield $(\%)=$ $Y\left(1-\mathrm{e}^{-k t}\right)$, where $k=k_{\text {obs }}$ and $Y=$ final yield.

General Method for Labeling of RNA with GTP Analogues and Terbium-Assisted 10DM24 Deoxyribozymes. The target RNA (0.5-4 nmol), the respective deoxyribozyme, and $\mathrm{R}_{\Delta}$ were mixed in a 1:1:1.5 ratio and annealed (as for kinetic assays). Next, 4 equiv of GTP analogue with respect to target RNA was added, and the reaction was performed at room temperature or at $37^{\circ} \mathrm{C}$ for $3-5 \mathrm{~h}$ in $50 \mathrm{mM}$ HEPES pH 7.5, $150 \mathrm{mM} \mathrm{NaCl}, 2 \mathrm{mM} \mathrm{KCl}, 100 \mu \mathrm{M} \mathrm{TbCl}_{3}$, and 20 or $80 \mathrm{mM} \mathrm{MgCl}$. The final concentration of target RNA was 5, 10 , or $20 \mu \mathrm{M}$, and the final concentration of labeled GTP was therefore 20,40 , or $80 \mu \mathrm{M}$. Nucleic acids were precipitated with ethanol and separated by denaturing PAGE. Isolated yields of labeled RNAs ranged from 25 to $62 \%$. The deoxyribozymes were re-isolated and used for subsequent reactions.

Thermal Melting Analysis of RNA Duplexes. UV melting curves were recorded and analyzed as previously described. ${ }^{8}$ Duplex concentrations were 0.4 or $2 \mu \mathrm{M}$ in $10 \mathrm{mM}$ sodium phosphate $\mathrm{pH} 7$ with $150 \mathrm{mM} \mathrm{NaCl}$.

Analysis of SAM-II RNA: Ligand Binding and Pseudoknot Folding Monitored by 2AP Fluorescence and FRET. Fluorescence titration experiments for measuring $K_{\mathrm{D}, \mathrm{app}}$ were performed essentially as previously described. ${ }^{1,26}$ For 2 AP fluorescence: excitation, $308 \mathrm{~nm}$; emission area integration, 325-500 nm. For FRET with donor C488 and acceptor F545: excitation, $496 \mathrm{~nm}$; donor emission, $520 \mathrm{~nm}$; acceptor emission, $585 \mathrm{~nm}$. FRET efficiency was calculated as $E=1-I_{\mathrm{DA}} / I_{\mathrm{D}}$, with $I_{\mathrm{DA}}$ the donor emission intensity of double-labeled RNA and $I_{\mathrm{D}}$ the donor emission intensity of donoronly-labeled RNA. Further details are given in the Supporting Information.

Analysis of Labeling Efficiency by RNA-Cleaving Deoxyribozymes. Analytical aliquots of fluorescently labeled U6 or ydaO 
RNA (containing traces of ${ }^{32} \mathrm{P}$ body-labeled transcripts) isolated from DNA-catalyzed labeling reactions were annealed with 2 -fold excess of the respective RNA-cleaving deoxyribozyme (10-23 or 8-17 DNAs, see Supporting Information for sequences) and incubated with $20 \mathrm{mM}$ $\mathrm{MgCl}_{2}$ and $20 \mathrm{mM} \mathrm{MnCl}_{2}$ in $1 \times$ reaction buffer $(40 \mathrm{mM}$ Tris $\mathrm{HCl} \mathrm{pH}$ $7.5,150 \mathrm{mM} \mathrm{NaCl}$ ) for $1.5 \mathrm{~h}$ at $37^{\circ} \mathrm{C}$. The samples were analyzed by denaturing PAGE, and the RNA fragments were visualized by PhosphorImaging and fluorescence imaging.

\section{ASSOCIATED CONTENT}

\section{(S Supporting Information}

Additional information as noted in the text, including Figures S1-S18 and Tables S1-S4; sequence information on all RNA and DNA oligonucleotides used in this work; and methods for chemical synthesis of TA and BPA. This material is available free of charge via the Internet at http://pubs.acs.org.

\section{AUTHOR INFORMATION}

\section{Corresponding Author}

claudia.hoebartner@mpibpc.mpg.de

\section{Present Address}

${ }^{\dagger}$ Department of Biology, Faculty of Sciences, University of Isfahan, Iran

\section{Notes}

The authors declare no competing financial interest.

\section{ACKNOWLEDGMENTS}

L.B. acknowledges funding by an excellence fellowship from the Göttingen Graduate School for Neurosciences, Biophysics, and Molecular Biosciences (GGNB, DFG GSC 226/2). This work was supported by the Cluster of Excellence and DFG Research Center Nanoscale Microscopy and Molecular Physiology of the Brain (CNMPB), the International Research Training Group Metal Sites in Biomolecules (IRTG1422), and the Max Planck Society. We thank Uwe Pleßmann and Jürgen Bienert for measuring ESI-MS and NMR, and Giuseppe Sicoli for recording CW-EPR spectra.

\section{REFERENCES}

(1) RNA Structure and Folding; Klostermeier, D., Hammann, C., Eds.; Walter de Gruyter GmbH: Berlin, Germany, 2013.

(2) Solomatin, S.; Herschlag, D. Methods Enzymol. 2009, 469, 47.

(3) Weisbrod, S. H.; Marx, A. Chem. Commun. 2008, 44, 5675.

(4) Fauster, K.; Hartl, M.; Santner, T.; Aigner, M.; Kreutz, C.; Bister, K.; Ennifar, E.; Micura, R. ACS Chem. Biol. 2012, 7, 581.

(5) Lang, K.; Micura, R. Nat. Protoc. 2008, 3, 1457.

(6) Winz, M. L.; Samanta, A.; Benzinger, D.; Jäschke, A. Nucleic Acids Res. 2012, 40, e78.

(7) Paredes, E.; Evans, M.; Das, S. R. Methods 2011, 54, 251.

(8) Purtha, W. E.; Coppins, R. L.; Smalley, M. K.; Silverman, S. K. J. Am. Chem. Soc. 2005, 127, 13124.

(9) Büttner, L.; Seikowski, J.; Wawrzyniak, K.; Ochmann, A.; Höbartner, C. Bioorg. Med. Chem. 2013, 21, 6171.

(10) Motorin, Y.; Burhenne, J.; Teimer, R.; Koynov, K.; Willnow, S.; Weinhold, E.; Helm, M. Nucleic Acids Res. 2011, 39, 1943.

(11) Tomkuviene, M.; Clouet-d'Orval, B.; Cerniauskas, I.; Weinhold, E.; Klimasauskas, S. Nucleic Acids Res. 2012, 40, 6765.

(12) Onizuka, K.; Shibata, A.; Taniguchi, Y.; Sasaki, S. Chem. Commun. 2011, 47, 5004.

(13) Onizuka, K.; Taniguchi, Y.; Sasaki, S. Bioconjugate Chem. 2009, 20,799 .

(14) Onizuka, K.; Taniguchi, Y.; Sasaki, S. Bioconjugate Chem. 2010, 21, 1508.

(15) Baum, D. A.; Silverman, S. K. Angew. Chem., Int. Ed. 2007, 46, 3502
(16) Silverman, S. K.; Baum, D. A. Methods Enzymol. 2009, 469, 95.

(17) Willner, I.; Shlyahovsky, B.; Zayats, M.; Willner, B. Chem. Soc. Rev. 2008, 37, 1153.

(18) Schlosser, K.; Li, Y. Chem. Biol. 2009, 16, 311.

(19) Zelin, E.; Wang, Y.; Silverman, S. K. Biochemistry 2006, 45, 2767.

(20) Höbartner, C.; Silverman, S. K. Angew. Chem., Int. Ed. 2007, 46, 7420.

(21) Javadi-Zarnaghi, F.; Höbartner, C. J. Am. Chem. Soc. 2013, 135, 12839.

(22) Most commercial labeled GTP analogues are quite expensive, and often available only at low concentrations (e.g., at $1 \mathrm{mM}$ ).

(23) In an earlier study, Baum and Silverman used 10DM24 for ligation of a 17-nt-long tagging RNA at 10 adenosine target sites within the P4-P6 RNA of a group I intron. ${ }^{15}$

(24) Gilbert, S. D.; Rambo, R. P.; Van Tyne, D.; Batey, R. T. Nat. Struct. Mol. Biol. 2008, 15, 177.

(25) Corbino, K. A.; Barrick, J. E.; Lim, J.; Welz, R.; Tucker, B. J.; Puskarz, I.; Mandal, M.; Rudnick, N. D.; Breaker, R. R. Genome Biol. 2005, 6, R70.

(26) Haller, A.; Rieder, U.; Aigner, M.; Blanchard, S. C.; Micura, R. Nat. Chem. Biol. 2011, 7, 393.

(27) Lim, J.; Winkler, W. C.; Nakamura, S.; Scott, V.; Breaker, R. R Angew. Chem., Int. Ed. 2006, 45, 964.

(28) Chen, B.; Zuo, X.; Wang, Y. X.; Dayie, T. K. Nucleic Acids Res. 2012, 40, 3117.

(29) Karaduman, R.; Dube, P.; Stark, H.; Fabrizio, P.; Kastner, B.; Lührmann, R. RNA 2008, 14, 2528.

(30) Nelson, J. W.; Sudarsan, N.; Furukawa, K.; Weinberg, Z.; Wang, J. X.; Breaker, R. R. Nat. Chem. Biol. 2013, 9, 834.

(31) The ydaO RNA was earlier shown to bind ATP with millimolar affinity: Watson, P. Y.; Fedor, M. J. Nat. Chem. Biol. 2012, 8, 963.

(32) Haller, A.; Altman, R. B.; Souliere, M. F.; Blanchard, S. C.; Micura, R. Proc. Natl. Acad. Sci. U.S.A. 2013, 110, 4188.

(33) Souliere, M. F.; Altman, R. B.; Schwarz, V.; Haller, A.; Blanchard, S. C.; Micura, R. Proc. Natl. Acad. Sci. U.S.A. 2013, 110, E3256.

(34) Suddala, K. C.; Rinaldi, A. J.; Feng, J.; Mustoe, A. M.; Eichhorn, C. D.; Liberman, J. A.; Wedekind, J. E.; Al-Hashimi, H. M.; Brooks, C. L., 3rd; Walter, N. G. Nucleic Acids Res. 2013, 41, 10462.

(35) Currently, the separation of double-labeled RNA from singlelabeled and unlabeled molecules remains challenging when labeling positions need to be selected that cannot be efficiently cleaved by deoxyribozymes. Using $8-17$ and 10-23 deoxyribozymes, only AlG and AlU labeling sites can be cleaved with high efficiency; in our hands, alternative deoxyribozymes ${ }^{16,37}$ for $\mathrm{AlC}$ and $\mathrm{AlA}$ junctions were not efficient enough for long RNAs.

(36) Wachowius, F.; Javadi-Zarnaghi, F.; Höbartner, C. Angew. Chem., Int. Ed. 2010, 49, 8504.

(37) Cruz, R. P. G.; Withers, J. B.; Li, Y. Chem. Biol. 2004, 11, 57. 